\title{
Poly-(ADP-Ribose) Polymerase-1 Is Necessary for Long-Term Facilitation in Aplysia
}

\author{
A. Iván Hernández, ${ }^{1,2}$ Jason Wolk, ${ }^{1}$ Jiang-Yuan Hu, ${ }^{1}$ Jinming Liu, ${ }^{1}$ Takeshi Kurosu, ${ }^{1}$ James H. Schwartz, ${ }^{\dagger}$ \\ and Samuel Schacher ${ }^{1}$ \\ ${ }^{1}$ Department of Neuroscience, College of Physicians and Surgeons, Columbia University, New York State Psychiatric Institute, New York, New York 10032, \\ and ${ }^{2}$ Department of Pathology, State University of New York, Downstate Medical Center, Brooklyn, New York 11203
}

Activity-dependent long-term synaptic plasticity requires gene expression and protein synthesis. Identifying essential genes and studying their transcriptional and translational regulation are key steps to understanding how synaptic changes become long lasting. Recently, the enzyme poly-(ADP-ribose) polymerase 1 (PARP-1) was shown to be necessary for long-term memory (LTM) in Aplysia. Since PARP-1 decondenses chromatin, we hypothesize that this enzyme regulates the expression of specific genes essential for long-term synaptic plasticity that underlies LTM. We cloned Aplysia PARP-1 (APPARP-1) and determined that its expression in sensory neurons is necessary for serotonin (5-HT)-mediated long-term facilitation (LTF) of sensorimotor neuron synapses. PARP enzymatic activity is also required, since transient application of PARP inhibitors blocked LTF. Differential display and RNA analysis of ganglia dissected from intact animals exposed to 5-HT identified the ribosomal RNA genes as PARP-dependent effector genes. The increase in the expression of rRNAs is long lasting and dynamic. Pulse-labeling RNA studies showed a PARP-dependent increase in rRNAs but not in the total RNA $24 \mathrm{~h}$ after 5-HT treatment. Moreover, the expression of both the AprpL27a (Aplysia ribosomal protein L27a) and the ApE2N (Aplysia ubiquitinconjugating enzyme E2N) mRNAs also increased after 5-HT. Thus, our results suggest that 5-HT, in part by regulating PARP-1 activity, alters the expression of transcripts required for the synthesis of new ribosomes necessary for LTF.

\section{Introduction}

Formation of long-term memory (LTM) requires new gene expression and protein synthesis (Davis and Squire, 1984; Kandel, 2001). Long-term sensitization (LTS) of withdrawal reflexes in Aplysia, and one of its physiological substrates, long-term facilitation (LTF) of sensorimotor neuron synapses, are tractable preparations for studying the cellular and molecular mechanisms of learning and memory (Montarolo et al., 1988; Buonomano and Byrne, 1990; Mauelshagen et al., 1996; Sutton and Carew, 2000; Sharma and Carew, 2004; Sutton et al., 2004).

Chromatin remodeling is essential for transcriptional regulation (Aalfs and Kingston, 2000). In Aplysia, regulating the transcription of several genes is essential for LTF (Noel et al., 1993, 1994; Alberini et al., 1994; Hegde et al., 1997; Zwartjes et al., 1998;

Received March 30, 2009; revised May 18, 2009; accepted June 19, 2009.

This work was supported by Grants MH60387 and MH48850 from the National Institute of Mental Health. We thank Dr. Juan Marcos Alarcon for reading this manuscript critically and Andrew Tcherepanov for technical help. Animals were provided by the National Center for Research Resources for Aplysia at the University of Florida in Miami, which is supported by National Institutes of Health Grant RR-10294. Dr. Schwartz was a founding member of the Center for Neurobiology and Behavior at Columbia University.

${ }^{\dagger}$ Deceased, March 13, 2006

Correspondence should be addressed to Samuel Schacher, Department of Neuroscience, College of Physicians and Surgeons, Columbia University, New York State Psychiatric Institute, 1051 Riverside Drive, New York, NY 10032 E-mail:sms2@columbia.edu.

A. I. Hernández' present address: Department of Pathology, SUNY Downstate Medical Center, 450 Clarkson Avenue, Box 25, Brooklyn, NY 11203. E-mail: ivan.hernandez@downstate.edu.

T. Kurosu's present address: Thailand-Japan Research Collaboration Center on Emerging and Re-emerging Infections, Thailand National Institute of Health, Department of Medical Sciences, 88/7 Soi Bamrasnaradura, Tivanond Road, Nonthaburi 11000, Thailand. E-mail: tkurosu@biken.osaka-u.ac.jp.

D0I:10.1523/JNEUROSCI.1512-09.2009

Copyright $\odot 2009$ Society for Neuroscience $\quad$ 0270-6474/09/299553-10\$15.00/0
Bartsch et al., 2000; Giustetto et al., 2003). Chromatin remodeling plays a crucial role in regulating the expression of $A p C / E B P$ (Guan et al., 2002). Transcription factors and enzymes are recruited to its promoter to modify the structure of the chromatin, allowing the DNA either to be exposed or to be hidden from the transcription machinery. Stimuli that induce LTF promote the upregulation of $A p C / E B P$ by activating CREB1 (cAMP response element-binding protein 1) to recruit CBP (CREB-binding protein), a histone acetylase, which allows the opening of chromatin at the $A p C / E B P$ promoter, facilitating transcription (Guan et al., 2002). In contrast, the inhibitory neuropeptide Phe-Met-ArgPhe-NH2 (FMRFa), which produces long-term depression, activates p38 MAP (mitogen-activated protein) kinase, which is then transported into the nucleus to phosphorylate and activate the inhibitory transcription factor CREB2. Activated CREB2 displaces CREB1 and recruits histone deacetylase 5 (HDAC5), causing condensation of the DNA and the downregulation of $A p C /$ EBP gene transcription (Guan et al., 2002, 2003). CREB2 may also act alone as an activator of transcription, perhaps by affecting chromatin structure (Fioravante et al., 2008).

Another family of proteins important for regulating chromatin remodeling is the poly-(ADP-ribose) polymerase (PARP) family of enzymes. This family catalyzes the rapid and transient polymerization of ADP-ribose on acceptor proteins that bind or interact with DNA. PARP-1, the major and most extensively studied PARP, is a nuclear protein of $116 \mathrm{kDa}$ containing three functional domains: an N-terminal DNA-binding domain, an automodification domain, and a C-terminal catalytic domain. PARP-1 activation produces posttranslational modification of 


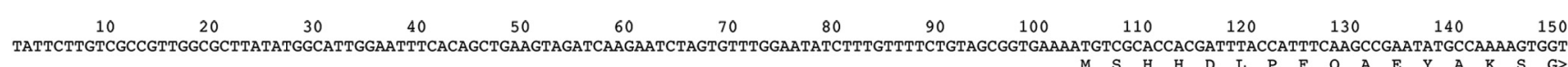

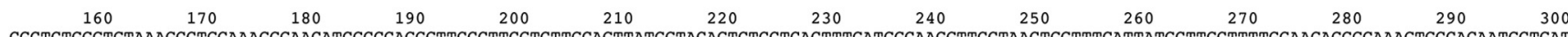

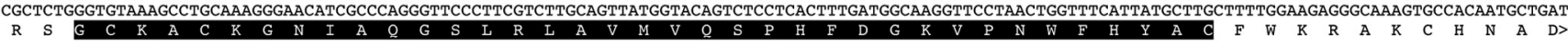

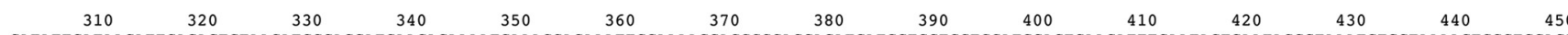

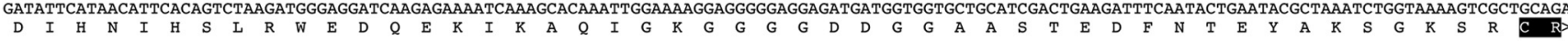

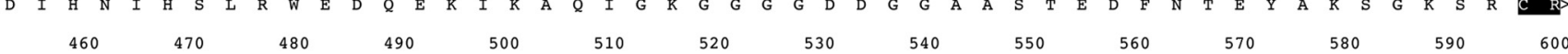
GGATGTGAGGAGAATATTGCTAAGGATAGCCTTCGCATCAGCAAGAAGGAATATGAATCTCAGAGAGCCAAGATGTACGGACCCCAGGACTTGTGGCATCATGTTGACTGCTTTGTGGACAAACGAGACGAGCTTGGCTTTACTGAACAG

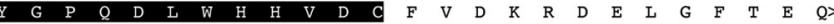

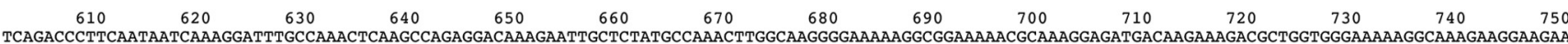
S D S I I K G F A T A

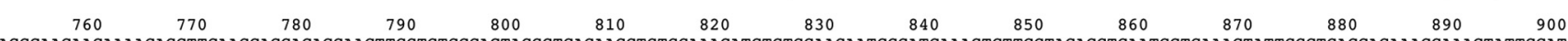

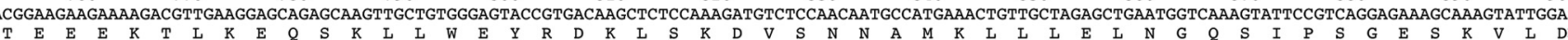

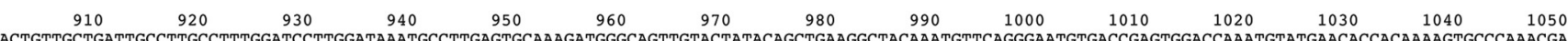

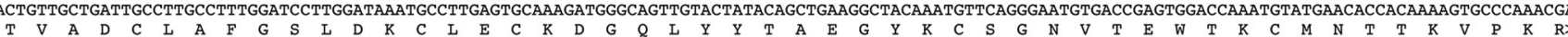

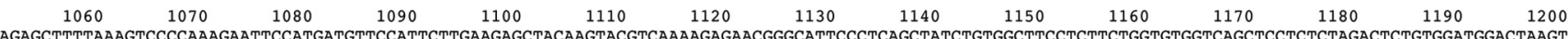

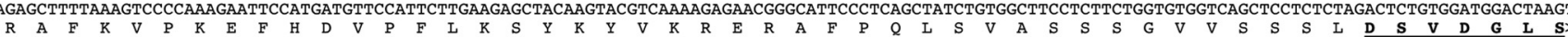
$\begin{array}{llllllllllllllllll}1210 & 1220 & 1230 & 1240 & 1250 & 1260 & 1270 & 1280 & 1290 & 1300 & 1310 & 1320 & 1330 & 1340 & 1350\end{array}$ AGTGAAAAACCGCTGCAAGACTTGAAGTTTGTCATTCAAGGGAAGCTGGGGAAGAGCAAAGCTCAAGTGACCAGTGACATCTCCAAGAAGGGAGGCGTGGTAGTGACAAAGGTGGACAAAAAAGTGGCGGCTGTCATCAGCAACAAAGAT

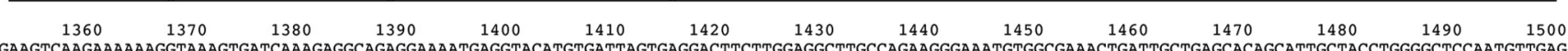

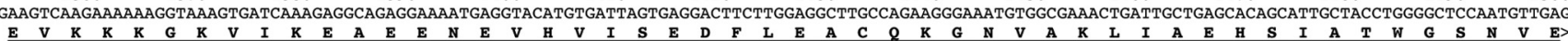

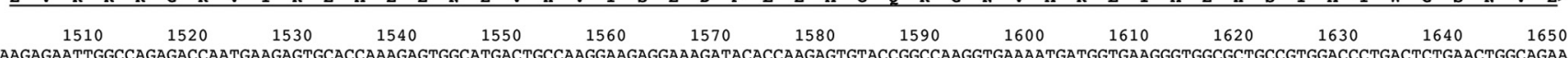

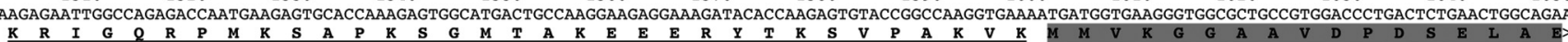

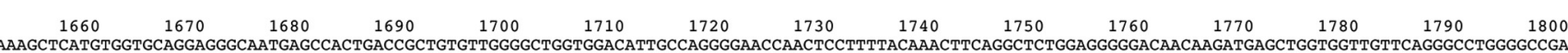

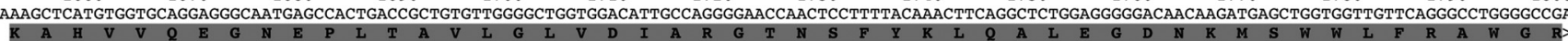

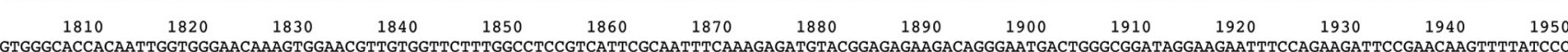

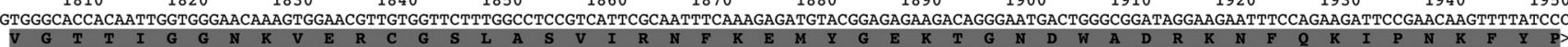

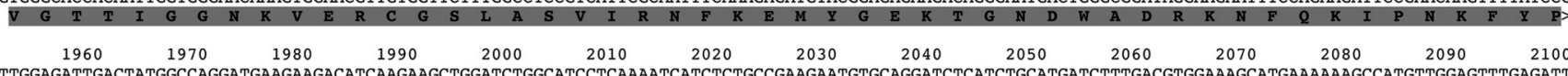

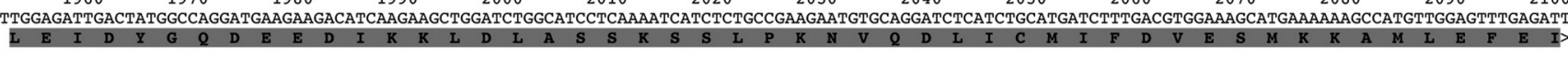

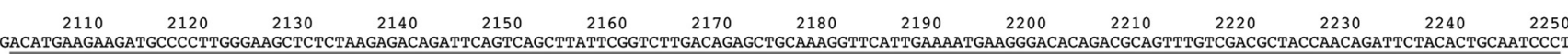

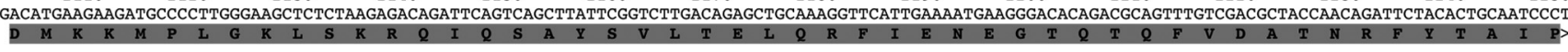

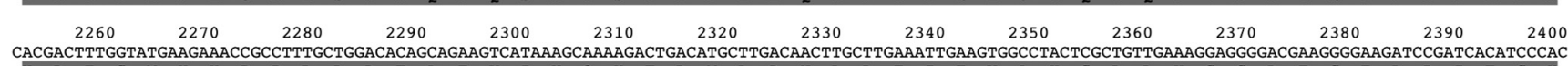

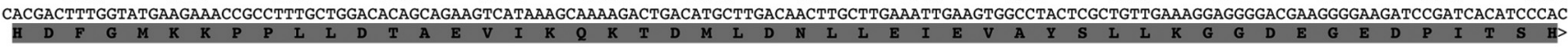
$\begin{array}{cccccccccccc}2410 & 2420 & 2430 & 2440 & 2450 & 2460 & 2470 & 2480 & 2490 & 2500 & 2510 & 2520\end{array}$

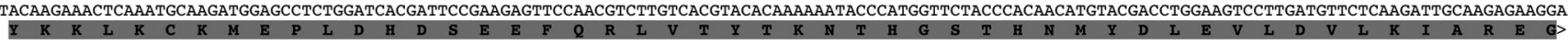

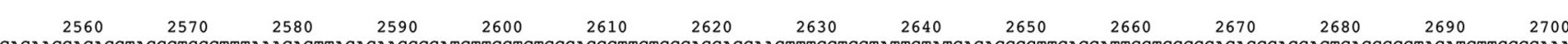

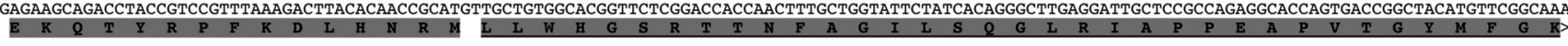
$\begin{array}{lllllllllllll}2710 & 2720 & 2730 & 2740 & 2750 & 2760 & 2770 & 2780 & 2790 & 2800 & 2810 & 2820 & 2830\end{array}$ GGTGTTIACTITGCCGACATGGTCACCAAGAGTGCCAACTACTGCCGCACGTCCAAGACGGACAACATCGGAGTCATGCTGCTCTGTGAGGTCGCCCTIGGCAACATGTATGAGCTGACGCACTCTGAGTTTGTCAATAAGTTACCGAAA

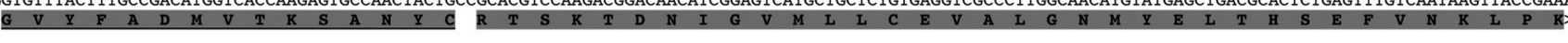

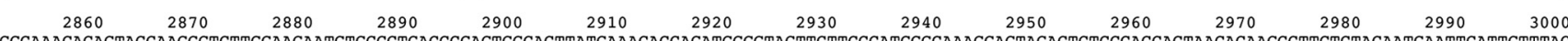

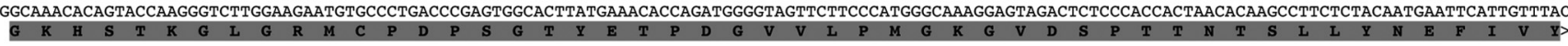

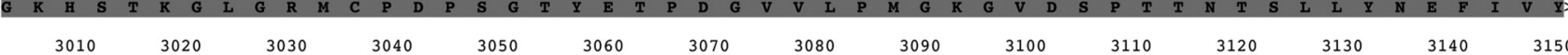

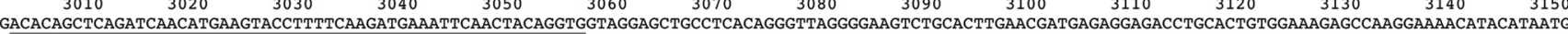

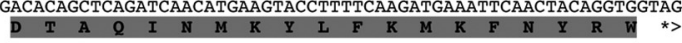

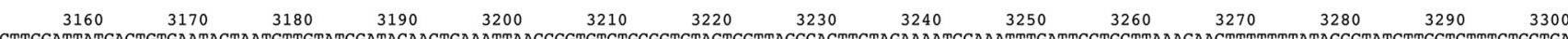

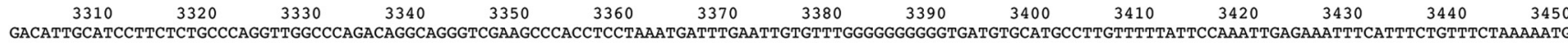

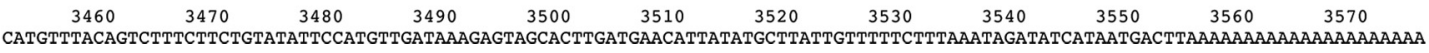

Figure 1. Characterization of APPARP-1 sequence. The N-terminal sequence contains the conserved zinc fingers (white letters in black background; subdomain A or amino acids 19 -55 and amino acids 115-153) followed by the nuclear localization signal (white letters in gray background; subdomain B or amino acids 192-214) and the automodification domain (underlined bold letters; subdomain D or amino acids 360 - 499). Within the catalytic domain (bold letters in gray background or amino acids 500-985) the "PARP signature" is shown (bold letters underscored in gray background; subdomain F or amino acids 832-881).

nuclear proteins affecting their interaction with DNA (D'Amours et al., 1999; Virag and Szabo, 2002).

PARP- 1 activation has chiefly been studied in pathophysiological conditions of oxidative stress and DNA damage (D'Amours et al., 1999; Virag and Szabo, 2002). Activation of PARP also occurs in situations other than DNA repair (Homburg et al., 2000; Tulin et al.,
2002; Tulin and Spradling, 2003; Cohen-Armon et al., 2004, 2007; Kim et al., 2005; Visochek et al., 2005; Cohen-Armon, 2007). Recent studies indicate that after treatment with serotonin $(5-\mathrm{HT})$ or after training, PARP-1 is activated in the ganglia of Aplysia that mediate several forms of long-term memory in Aplysia, including LTS. In addition, PARP inhibitors blocked long-term memory, suggesting a 

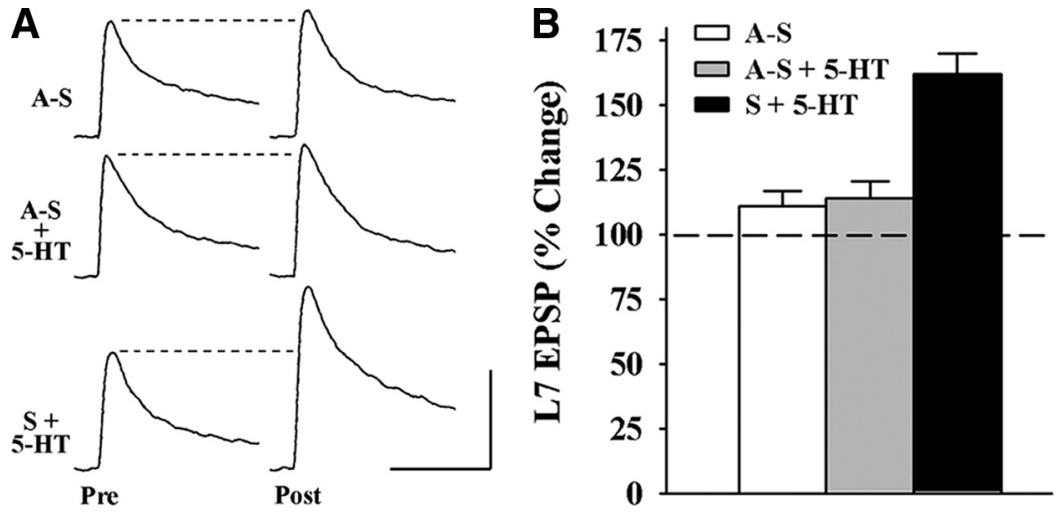

Figure 2. ApPARP-1 expression is necessary for LTF. A, EPSPs were recorded in L7 before (Pre) and $24 \mathrm{~h}$ after (Post) 5 applications of 5-HT. APPARP-1 antisense (A-S) blocked the increase in amplitude when injected into the sensory neuron $12 \mathrm{~h}$ before 5 -HT treatment (A-S + 5-HT). In contrast, the reverse sequence of the antisense $(S)$ did not affect LTF $(S+5$-HT). In addition, injections of A-S did not affect baseline synaptic transmission (A-S). Vertical bar, $20 \mathrm{mV}$; horizontal bar, $25 \mathrm{~ms}$. B, Ap-PARP-1 antisense blocked LTF produced by 5 -HT. The height of each bar is the percentage change + SEM in the amplitude of the EPSP $24 \mathrm{~h}$ after the indicated treatments. The dashed line at $100 \%$ indicates no change with time. ANOVA indicated a significant effect of treatment (df $=2,15 ; F=17.285 ; p<0.001$ ). Individual comparisons (Scheffe $F$ test) indicated that 5 -HT applied after injection of ApPARP-1 antisense (gray bar) significantly reduced LTF compared with 5-HT applied after injection of sense oligonucleotide (black $\operatorname{bar})(F=12.263, p<0.01)$. Injection of antisense oligonucleotide alone (A-S) did not affect synaptic baseline, and the change in EPSP was not significantly different from the change produced by $5-\mathrm{HT}$ applied after injection of the antisense.

role in the expression of genes essential for LTM (Cohen-Armon et al., 2004). Is PARP activity required for the expression of LTF in sensorimotor neuron synapses, one of the cellular analogs of LTS, and does it regulate the expression of specific genes? We cloned and sequenced APPARP-1 and demonstrate that its expression in sensory neurons and its activity are necessary for LTF at sensorimotor neuron synapses. In addition, PARP activity is needed for increases in some ribosomal components produced by 5 -HT, suggesting that chromatin remodeling by PARP is critical for the expression of genes associated with the new translation required for persistent synaptic change.

\section{Materials and Methods}

Sequencing. A short sequence for APPARP-1 was obtained from archives of the Aplysia genome project (Moroz et al., 2006). The fulllength cDNA sequence was completed by reverse transcription of total RNA sample from ganglia of adult animals $(60-80 \mathrm{~g})$ followed by $5^{\prime}$ and $3^{\prime}$ extension using GenRacer Kit (Invitrogen). Aplysia ribosomal protein L27a (AprpL27a) and Aplysia ubiquitin-conjugating enzyme E2N $(A p E 2 N)$ mRNAs were cloned and sequenced using differential display followed by $5^{\prime}$ and $3^{\prime}$ extension using GenRacer Kit. The program MacVector 9.5.2 (MacVector) was used to determine homologies and motifs. The accession numbers for the sequences are GQ389636 for ApE2N, GQ389637 for AprpL27a, and GQ389638 for PARP-1.

Cell culture and electrophysiology. Sensory neurons were isolated from pleural ganglia dissected from adult animals $(60-80 \mathrm{~g})$ and L7s were isolated from juvenile abdominal ganglia $(2 \mathrm{~g})$ and maintained in coculture for $5 \mathrm{~d}$ (Montarolo et al., 1986). Standard electrophysiological techniques were used to record EPSP amplitudes evoked in L7. L7s were held at $-85 \mathrm{mV}$. EPSP amplitudes were recorded before and $24 \mathrm{~h}$ after various treatments after sensory neurons were stimulated with an extracellular electrode placed near the cell body of the sensory neuron to produce a single action potential. LTF was produced by five repeated bath applications of $5-\mathrm{HT}(5 \times 5-\mathrm{HT} ; 5 \mu \mathrm{M}$ for $5 \mathrm{~min})$ at $20 \mathrm{~min}$ intervals. ApPARP-1 antisense 5'-GTAAATCGTGGTGCGACATTTTCAC-3' or its reverse sequence (control) 5' -CACTTTTACAGCGTGGTGCTAAATG-3' was dissolved in $0.5 \mathrm{M} \mathrm{KCl}$ and $10 \mathrm{mM} \mathrm{K}^{+}$-HEPES, $\mathrm{pH} 7.4$, at a concentration of $0.3 \mathrm{~mm}$ and then pressure injected into cell bodies $12 \mathrm{~h}$ before treatments with 5-HT. LTF was assessed $24 \mathrm{~h}$ after $5 \times 5$-HT. PARP inhibitor 3 -aminobenzamide (3AB; Sigma) at $100 \mu \mathrm{M}$ or PJ34 (Sigma) at $1 \mu \mathrm{M}$ was added to the bath $15 \mathrm{~min}$ before the first application of 5-HT and was present until $15 \mathrm{~min}$ after the last application of 5 -HT. In addition, $3 \mathrm{AB}$ at $100 \mu \mathrm{M}$ was added $6 \mathrm{~h}$ before, right after, or $2 \mathrm{~h}$ after $5 \times 5-\mathrm{HT}$. The inhibitor was washed out and cultures were incubated in normal culture medium for re-examination of the EPSPs at $24 \mathrm{~h}$.

LTS in vivo. We used the in vivo protocol developed by Alberini et al. (1994). Animals were exposed to $250 \mu \mathrm{m} 5$-HT in artificial seawater (ASW) for $120 \mathrm{~min}$. Control animals were exposed to ASW alone for the same time as stimulated animals. The temperature used for these experiments $\left(15-17^{\circ} \mathrm{C}\right)$ was tightly controlled. The experiments and dissection were done during the daytime to avoid significant changes in gene expression resulting from circadian cycle (Hattar et al., 2002; Lyons et al., 2006). In addition, the animals used were not fed on the day of the experiment. We have observed that feeding during the day of treatment increases levels of the immediate early and stimulus-regulated gene, $A p C / E B P$. We also excluded whole-animal and ganglion experiments during June-September, because expression of $A p C / E B P$ is reduced significantly during the warmer seasons (our unpublished observations).

PARP inhibition in vivo. Animals were injected with $5 \mathrm{~mm} 3 \mathrm{AB}$ in ASW $(2 \mathrm{ml} / 90 \mathrm{~g}$ of body mass) 10 min before $(-10)$ the start time of 5 -HT treatment that produces in vivo LTS. After the $2 \mathrm{~h}$ treatment, the animals were anesthetized with $50 \mathrm{ml}$ of $\mathrm{MgCl}_{2}(370 \mathrm{~mm})$. Central ganglia were rapidly removed and prepared for total RNA purification. Control groups injected with ASW (at - $10 \mathrm{~min}$ ) were incubated for $2 \mathrm{~h}$ in ASW containing 5-HT or in ASW alone. These samples were used for differential display, total RNA and $18 S$ and $28 S$ rRNA quantification, and real-time PCR quantification using relative levels of $A p C / E B P$ with respect to histone $4(A p H 4)$.

Time course analysis. To test long lasting effects of 5-HT, Aplysia were exposed to the treatment described by Alberini et al. (1994), except for the group treated for $1 \mathrm{~h}$. In the 1 and $2 \mathrm{~h}$ groups, the ganglia were rapidly removed after 5-HT treatment and prepared for total RNA purification. In the groups examined $4,6,9$, and $20 \mathrm{~h}$ after $2 \mathrm{~h}$ in 5 -HT, the animals were placed in ASW until the appropriate time point, and then ganglia were rapidly removed for RNA purification. During the first $60 \mathrm{~min}$ after withdrawal from 5-HT, the ASW was replaced every $20 \mathrm{~min}$ and then the animals were left in ASW. RNA that was isolated was used to quantify total RNA and $18 S$ and $28 S$ rRNA and for real-time PCR quantification to measure the expression of $h t 28 S$ (unedited 28S), AprpL27a, ApE2N, and ApC/EBP normalized to the expression of Aplysia histone 4 (ApH4).

Total RNA isolation. Total RNA was purified with TRIzol reagent (Invitrogen), precipitated with ethanol, and resuspended in $20 \mathrm{ml}$ of DEPCtreated water for digestion with DNase I (RNase free). The total RNA was repurified with TRIzol and $5 \mu \mathrm{g}$ was used for reverse transcription using random hexamers as primers. The RNA purity was assessed by its 260 / 280 optical density (OD) ratio.

Reverse transcription. Five micrograms of total RNA from ganglia was used for reverse transcription using the protocol provided by the Superscript III kit for random hexamers (Invitrogen) with the inclusion of 20 min at $42^{\circ} \mathrm{C}$ before the $50 \mathrm{~min}$ incubation at $50^{\circ} \mathrm{C}$. After $20 \mathrm{~min}$ of RNA digestion with RNase $\mathrm{H}$ at $37^{\circ} \mathrm{C}$, the cDNA was ready to be used for relative quantification of gene expression.

Differential display. To detect the 275 bp band ( 28 S rRNA), we used the following primers with arbitrary but defined sequences: BS54, AACGCGCAAC; and BS55, GTGGAAGCGT [for the differential display technique see Sokolov and Prockop (1994) and Polesskaya et al. (2003)]. The cDNA samples were amplified (GeneAmp PCR system 9700, Applied Biosystems) $\left(50\right.$ cycles: $20 \mathrm{~s}$ at $94^{\circ} \mathrm{C}, 1 \mathrm{~min}$ at $34^{\circ} \mathrm{C}, 1 \mathrm{~min}$ at $72^{\circ} \mathrm{C}$ ) and then run in 5\% PAGE gels to identify differentially expressed bands. PCR products were then run in agarose gels, the identified bands were cut, and the DNA was extracted using a MinElute kit (Qiagen). Resulting 
A

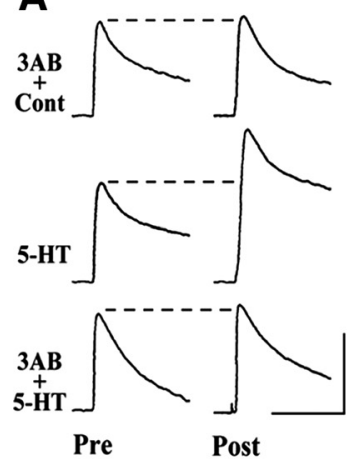

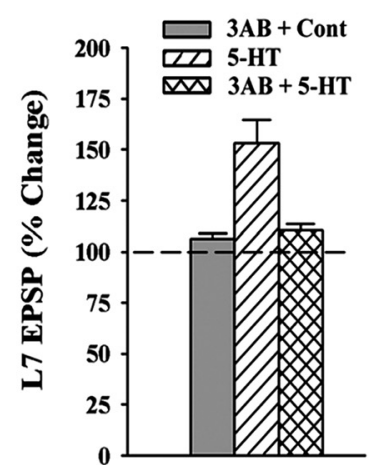

B

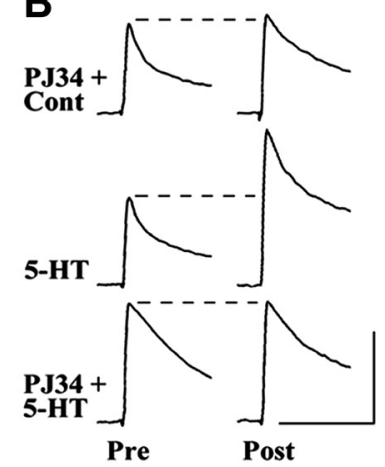

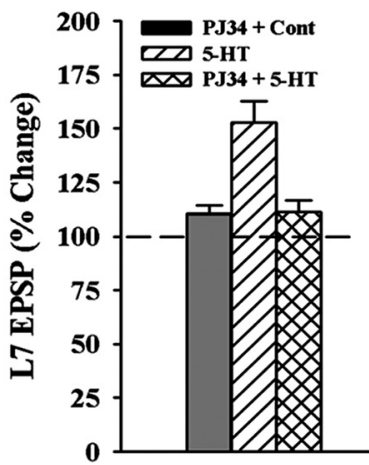

Figure 3. Application of PARP inhibitors during 5 -HT treatment blocks $24 \mathrm{~h}$ LTF. PARP inhibitor $3 A B(\boldsymbol{A})$ or PJ34 ( $\boldsymbol{B})$ blocks $24 \mathrm{~h}$ LTF when the drug is applied during 5 -HT applications. $\boldsymbol{A}, \boldsymbol{B}$, Left, EPSPs were recorded in L7 before (Pre) and $24 \mathrm{~h}$ after (Post) 5 -HT. Incubation with either $3 A B$ ( $3 A B+$ Cont) or PJ34 (PJ34 + Cont) did not affect synaptic baseline. Applications of 5 -HT produced a significant change in EPSP amplitude that was blocked when 5-HT was applied in the presence of drug (3AB $+5-\mathrm{HT}$ and PJ34 +5 -HT). Vertical bar, $20 \mathrm{mV}$; horizontal bar, $25 \mathrm{~ms}$. Right, The histograms indicate that blocking PARP activity with either $3 A B$ or PJ34 blocked LTF at $24 \mathrm{~h}$. The height of each bar is the average change + SEM in the EPSPs $24 \mathrm{~h}$ after the indicated treatments. The dashed line at 100\% indicates no change in EPSP. ANOVA indicated an effect of treatment for both drugs $(\boldsymbol{A}$ : df $=2,18 ; F=13.872 ; p<0.001 ;$ and $\boldsymbol{B}$ : df $=2,13 ; F=11.9 ; p<0.002)$. Individual comparisons indicate that $3 A B$ or PJ34 blocked LTF; $3 A B+$ Cont was not significantly different from $3 A B+5$-HT and PJ34 + Cont was not significantly different from PJ34 + 5-HT. In contrast, 5 -HT produced significant increases in the EPSP compared with $3 \mathrm{AB}+$ Cont $(F=11.372, p<0.01), 3 \mathrm{AB}+5$-HT $(F=9.336, p<0.01), \mathrm{PJ} 34+C$ ont $(F=$ $8.316, p<0.01)$, and PJ34 + 5-HT $(F=9.737, p<0.01)$.

purified DNA fragments were cloned with the TOPO TA cloning kit using the pCR 2.1 TOPO vector (Invitrogen) protocol in TOPO TA (cloning manual version $\mathrm{R}$ ) and their purity was verified by $5 \%$ PAGE. The full-length cDNA was determined using $5^{\prime}$ and $3^{\prime}$ rapid amplification of cDNA ends. Basic local alignment search tool (BLAST) homology searches identified matching sequences.

RNA gel quantification. One microgram of total RNA was loaded in each lane of an agarose (1\%)-formaldehyde-3-( $N$-morpholino)propanesulfonic acid (MOPS) RNA gel (Molecular Cloning, second edition). The top band in each lane $(18 \mathrm{~S}+28 \mathrm{~S}$ rRNA) was quantified in Adobe Photoshop by the average pixel intensity (on a gray scale from 1 to 256 , with 1 being black and 256 white).

Real-time PCR. To determine the levels of expression of target genes, we compared their amounts to that of Aplysia histone $4(A p H 4)$ mRNA by real-time PCR (comparative Ct method using separate tubes; ABI GeneAmp 5700 sequence detection system; user bulletin \#2; Applied Biosystems). We used $10 \mathrm{ng}$ of cDNA as input for a $50 \mu \mathrm{l}$ total PCR for $A p H 4, A p R P L 27 a, A p E 2 N$, and $A p C / E B P$ quantification, whereas $5 \mathrm{ng}$ (1:1 dilution) was loaded for Ap ht $28 S$ rRNA quantification (because of its abundance). We used primers ApH4F1 5'-GCAAGACCGTCACAGCTATGG-3' and ApH4R1 5' -TCTGAACGTTTGGGTTGGGT-3' for ApH4 (101 bp target), ApRPL27aF1 5'-GTACCTCCTGGCCAAACCCT-3' and ApRPL27aR1 5' ${ }^{\prime}$-CGGGTCTCTTGGGAAGATGAC-3' for ApRPL27a (101 bp target), ApE2NF1 5'-ACAACGGCTCATGGCAGAG-3' and ApE2NR1 5'-GAGACTGTGAAGGGCCAGCT-3' for ApE2N (101 bp target), ApC/EBPF1 5' -AACAGTTCCCTGGACAGCCA-3' and ApC/ EBPR1 5'-GAGGAGGCAGCACTGACCC-3' for ApC/EBP (151 bp target), and last, ApHt28SF2 5'-AGGCAGCGGGAGTGTCTGT-3' and ApHt28SR1 $5^{\prime}$-TCTCGTCCGATCTGAGGTCG-3' for ApHt28S (129 bp target). The reaction mixtures were incubated at $50^{\circ} \mathrm{C}$ for $2 \mathrm{~min}(1 \mathrm{cycle}), 95^{\circ} \mathrm{C}$ for 10 $\min \left(1\right.$ cycle), $60^{\circ} \mathrm{C}$ for $1 \mathrm{~min}$ ( 1 cycle), and $95^{\circ} \mathrm{C}$ for $15 \mathrm{~s}$ followed by $60^{\circ} \mathrm{C}$ for $1 \mathrm{~min}$ (40 cycles). At the end of the protocol, a dissociation curve analysis was performed to determine the specificity of amplification with a start temperature of $60^{\circ} \mathrm{C}$.

Pulse-labeling analysis. The animals were weighed, placed in a bath of isotonic $\mathrm{MgCl}_{2} / \mathrm{ASW}(1: 1, \mathrm{v} / \mathrm{v})$ for $30 \mathrm{~min}$ at $4^{\circ} \mathrm{C}$, and then anesthetized by injection of cold isotonic $\mathrm{MgCl}_{2}$. After $5 \mathrm{~min}$ of anesthesia the pleuralpedal ganglia were isolated from the animal and pinned to silicone plastic in ice-cold dissecting buffer [ $230 \mathrm{~mm} \mathrm{NaCl}, 220 \mathrm{~mm} \mathrm{MgCl}_{2}, 10 \mathrm{~mm} \mathrm{KC1}$, and $10 \mathrm{~mm}$ HEPES (pH 7.8)]. The ganglia were desheathed and incubated in resting medium $\left[11 \mathrm{~mm} \mathrm{CaCl}_{2}, 460 \mathrm{~mm} \mathrm{NaCl}, 10 \mathrm{~mm} \mathrm{KCl}, 55 \mathrm{~mm}\right.$ $\mathrm{MgCl}_{2}, 20 \mathrm{~mm}$ Tris- $\left.\mathrm{HCl}(\mathrm{pH} 7.4)\right]$ for $30 \mathrm{~min}$ at $4^{\circ} \mathrm{C}$, transferred to 35 $\mathrm{mm}$ plates, and incubated at $4^{\circ} \mathrm{C}$ for $50 \mathrm{~min}$. Samples were taken from the cold room and maintained for $1 \mathrm{~h}$ at room temperature. Ganglia were washed for $10 \mathrm{~min}$ with L15 supplemented with salts to bring the final concentrations of salts to those of Aplysia saline ( $\mathrm{NaCl}, 460 \mathrm{~mm} ; \mathrm{KCl}, 10$ $\mathrm{mm} ; \mathrm{MgCl}_{2} \cdot 6 \mathrm{H}_{2} \mathrm{O}, 28 \mathrm{~mm} ; \mathrm{MgSO}_{4} \cdot 7 \mathrm{H}_{2} \mathrm{O}, 27 \mathrm{~mm} ; \mathrm{CaCl}_{2} \cdot 2 \mathrm{H}_{2} \mathrm{O}, 11$ $\mathrm{mm}$ ). The supplemented L15 also contains $\mathrm{NaHCO}_{3} 2 \mathrm{~mm}$, dextrose 35 $\mathrm{mm}$, HEPES-Na $10 \mathrm{~mm}$, L-glutamine $4 \mathrm{~mm}$, cold uridine $1.5 \mu \mathrm{M}$, and $1 \%$ (vol./vol.) of $100 \times$ antibiotic stock solution of streptomycin and penicillin (Sigma) $\mathrm{pH}$ adjusted to 7.6. Each pair of ganglia was separated and allowed to recover overnight at $18^{\circ} \mathrm{C}$ incubator. After recovery one pair of ganglia was stimulated with $5 \times 5$ min pulses of 5 -HT $(200 \mu \mathrm{M})$ at 20 min intervals. The other pair was treated with $5 \times 5$ min pulses of L15 without $5-\mathrm{HT}$ or $5-\mathrm{HT}$ plus $3 \mathrm{AB}(5-\mathrm{HT}+3 \mathrm{AB})(1 \mathrm{~mm})$. In the latter, before the $5-\mathrm{HT}+3 \mathrm{AB}$, there was a 15 min preincubation of $3 \mathrm{AB}(1 \mathrm{~mm})$ in the absence of 5-HT. The higher concentration of $3 \mathrm{AB}$ was used compared with dissociated cell culture because the sheath surrounding the ganglia affects the penetration of the drug. We used the same concentration as in experiments on intact ganglia by Cohen-Armon et al. (2004). After $21 \mathrm{~h}$ from the onset of 5-HT treatment, ganglia were incubated with L15 containing uridine (tritiated) at a final concentration of $1.5 \mu \mathrm{M}(66.6$ $\mu \mathrm{Ci} / \mathrm{ml})$. The duration of label incubation was chosen on the basis of earlier reports for the snail Lymnaea that indicated that a $2 \mathrm{~h}$ exposure to 5,6- ${ }^{3} \mathrm{H}$-uridine produced maximal levels of incorporation (Fulton et al., 2005). In addition, in our hands 3 and $4 \mathrm{~h}$ produce similar levels of incorporation. After the $3 \mathrm{~h}$ incubation, ganglia were flash frozen on dry ice and put in $-80^{\circ} \mathrm{C}$. Individual ganglia were weighed to determine total mass and put into $250 \mu \mathrm{l}$ of TRIzol for standard RNA purification (see above, Total RNA isolation). After purification, OD was measured and RNA was standardized to $500 \mathrm{ng} / \mu \mathrm{l}$. For rRNA counts, $1 \mu \mathrm{g}$ of total RNA was loaded in an agarose-formaldehyde-MOPS gel and the bands corresponding to the $18 \mathrm{~S} / 28 \mathrm{~S}$ were cut. Each gel slice was weighed and solubilized in $2 \times$ the gel mass (in milligrams) per milliliter of Qiagen QG buffer (from MinElute kit). The extracted and solubilized RNA was counted in $10 \mathrm{ml}$ of liquid scintillation fluid. For total RNA counts, $1 \mu \mathrm{g}$ of total RNA per sample was loaded in $5 \mathrm{ml}$ of liquid scintillation fluid for counting. Five microliters of input solution (initial radioactivity count in L15 medium) in $5 \mathrm{ml}$ of liquid scintillation fluid was quantified for initial radioactivity counting.

Statistics. To compare significance of differences between experimental groups in the electrophysiology and whole-animal experiments, we first used ANOVA followed either by Scheffe $F$ test (electrophysiology) or least significant difference (LSD; whole-animal experiments) as the post hoc test. If the heterogeneity of variances was significant, nonparametric analysis (Kruskal-Wallis) was used with the Mann-Whitney $U$ test to determine differences between groups. Paired $t$ test analysis was used in the pulse-labeling experiments to compare synthesis of total and rRNA levels in the pedal-pleural ganglia. 


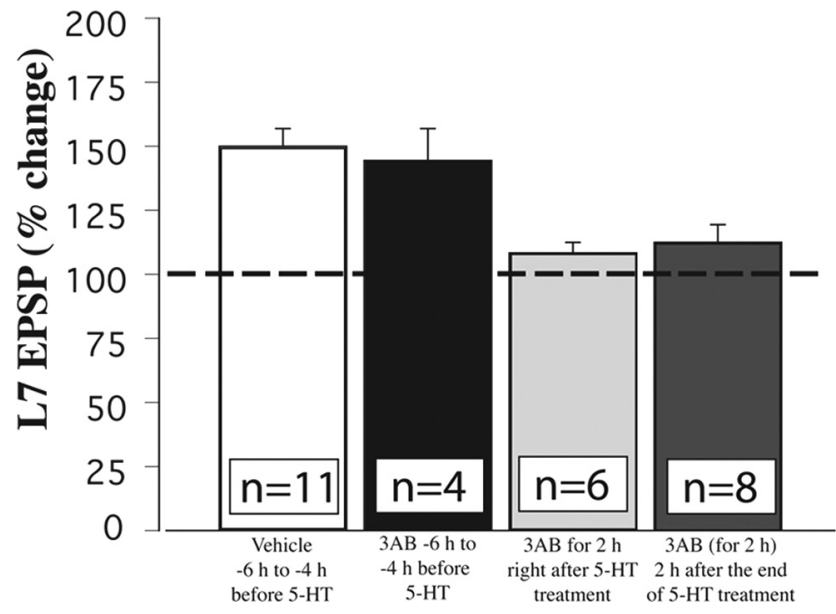

Figure 4. PARP inhibitor $3 A B$ applied after 5 -HT blocks LTF. PARP inhibitor $3 A B(100 \mu \mathrm{m})$ blocks $24 \mathrm{~h} \mathrm{LTF}$ when applied for $2 \mathrm{~h}$ immediately after (light gray bar) or $2 \mathrm{~h}$ after (dark gray bar) 5-HT. Exposure to vehicle (white bar) or $3 \mathrm{AB}$ (black bar) before 5-HT did not reduce LTF produced by 5 -HT after drug washout. ANOVA indicated a significant effect of treatment ( $\mathrm{df}=3,25 ; \mathrm{F}=$ $16.52 ; p<0.001)$. Individual comparisons indicated that vehicle and $3 \mathrm{AB}$ washout before 5 -HT were not significantly different from each other. Both of these groups were significantly greater than the changes in EPSP produced when $3 \mathrm{AB}$ was applied immediately after $5-\mathrm{HT}(F=9.156$, $p<0.01$ and $F=3.306, p<0.05)$ or $2 \mathrm{~h}$ after the end of $5-\mathrm{HT}(F=12.262, p<0.01$ and $F=$ $4.268, p<0.04)$.

\section{Results}

PARP-1 is activated in vivo after training that produces long-term modifications in feeding behavior and sensitization of withdrawal reflexes in Aplysia. In addition, PARP-1 activation was induced in isolated pleural-pedal ganglia by five pulses of 5-HT, a common way to produce several long-lasting cellular changes that accompany long-term sensitization, such as changes in excitability or in synaptic strength (Montarolo et al., 1986; Dale et al., 1987). PARP activation was proposed to be required for transient relaxation of chromatin, rendering DNA accessible to transcription (Cohen-Armon et al., 2004). To explore the role of PARP-1 in long-term changes in the strength of sensorimotor synapses, we cloned and sequenced Aplysia PARP-1 (ApPARP-1).

\section{Characterization of $A P P A R P-1$}

The PARP-1 enzyme is divided into three functional domains; a $46 \mathrm{kDa}$ N-terminal DNA-binding domain, a $22 \mathrm{kDa}$ automodification domain, and a $54 \mathrm{kDa}$ catalytic domain (Kameshita et al., 1984). As is the case for other PARP-1 enzymes, the DNAbinding domain of ApPARP-1 can be divided into three subdomains (A-C), followed by the automodification domain (D) and two domains within the catalytic domain (E and F) (de Murcia and Menissier de Murcia, 1994) (Fig. 1). At the cDNA level, the ApPARP-1 sequence presents polymorphisms (supplemental Table 1, available at www.jneurosci.org as supplemental material). Most polymorphisms correspond to silent mutations; the others are replacement of hydrophobic amino acids at position 264 and 418 and a basic amino acid replacement at position 317 . With BLAST, ApPARP-1 was found to share similarities with PARP-1 from other species. The highest homology is within the catalytic domain, nucleotide sequence 1699-3050 (Fig. 1), in which it shares 67-68\% homology with Mus musculus, Equus caballus, Danio rerio, and Homo sapiens. An alignment of the full-length amino acid sequence as well as phylogenetic tree analyses indicates that $A p P A R P-1$ shares 50-52\% identity with $P A R P-1$ from vertebrates such as Danio rerio, Mus musculus, Monodelphis do- mestica, Cricetulus griseus, Xenopus laevis, Rattus norvegicus, and Homo sapiens. In contrast, $A p P A R P-1$ identity with $P A R P-1$ from invertebrates such as Sarcophaga peregrina and Drosophila melanogaster is 46 and $42 \%$, respectively. The higher homology to vertebrates is conserved in motif analysis of the zinc finger I and PARP signature(s) (amino acids 19-55 and amino acids 832881), but not zinc finger II (amino acids 115-153). In addition, many putative phosphorylation sites were identified (supplemental Table 2, available at www.jneurosci.org as supplemental material). These include several putative sites that may be phosphorylated by kinases activated by 5 -HT [PKA (protein kinase A), PKC (protein kinase C), and ERK (extracellular signalregulated kinase)].

\section{ApPARP-1 is necessary for LTF}

$A p P A R P-1$ is activated during 5-HT treatment and after training that produces LTM. In addition, the general PARP inhibitor $3 \mathrm{AB}$ blocks LTM (Cohen-Armon et al., 2004). We tested whether PARP-1 expression in sensory neurons is necessary for LTF of sensorimotor neuron synapses in culture produced by repeated applications of 5-HT (Montarolo et al., 1986). Using a blind procedure, ApPARP-1 antisense oligonucleotide (A-S) or control oligonucleotide was injected into the cell bodies of sensory neurons $12 \mathrm{~h}$ before treatment with 5-HT. Injection of the antisense oligonucleotide blocked $24 \mathrm{~h}$ LTF (Fig. 2). In contrast, injection of the control oligonucleotide (S) had no effect on LTF produced by 5 -HT. Injecting the antisense oligonucleotide did not affect baseline synaptic transmission. These results suggest that interfering with the expression of PARP-1 in the presynaptic sensory neuron can abolish LTF produced by 5-HT, suggesting that PARP-1 expression in the presynaptic sensory neuron is necessary for LTF.

Previous studies indicated that PARP-1 regulates some functions independently of its enzymatic activity (for review, see Schreiber et al., 2006). To determine whether PARP activity is necessary for LTF at sensorimotor neuron synapses, we examined whether application of PARP inhibitors can regulate LTF produced by 5-HT. Application of PARP inhibitor 3AB (Fig. $3 A$ ) or PJ34 (Fig. 3B) 15 min before and during repeated applications of 5 -HT treatment (inhibitor present for a total of $2 \mathrm{~h}$ ) blocked LTF. Incubation with the inhibitors alone did not affect baseline synaptic efficacy. In addition, the inhibitors did not affect short-term synaptic efficacy recorded immediately after a single application of 5-HT. In both the control and 3AB-treated cultures $(n=3$ each), EPSP amplitude increased by $>80 \%$ (data not shown). Thus, PARP activity in the sensory neurons (Fig. 2) and/or motor neuron L7 is required for LTF.

What is the critical time window for PARP activity in the expression of LTF? To explore whether PARP activity is required after treatment with 5-HT that produces LTF, we applied $3 \mathrm{AB}$ for $2 \mathrm{~h}$ at various time points before or after 5-HT treatment (Fig. 4). Applications of $3 \mathrm{AB}$ before 5 -HT treatment $(-6 \mathrm{~h}$ to $-4 \mathrm{~h}$ ) failed to interfere with LTF produced by $5-\mathrm{HT}$. This indicates that the action of the inhibitor reverses rapidly. In contrast, inhibitor applied for $2 \mathrm{~h}$ immediately after 5 -HT or between +2 and $+4 \mathrm{~h}$ after 5-HT blocked the expression of LTF. In addition to the absence of a drug effect on baseline synaptic transmission and short-term facilitation, $3 \mathrm{AB}$ does not produce a subtle long-lasting toxic effect that would interfere with LTF. Thus, PARP activity both during and after 5-HT treatment is necessary for the expression of LTF. This suggested that PARP activity may produce a dynamic regulation of gene expression that is required for LTF. 
rRNAs are upregulated by 5-HT and PARP activity

LTF of sensory neuron synapses requires new protein synthesis and gene expression (Montarolo et al., 1986). To identify genes induced during 5-HT treatment and regulated by PARP, we isolated total RNA from ganglia of intact animals treated in three different conditions: a control group, injected with vehicle $10 \mathrm{~min}$ before a $2 \mathrm{~h}$ incubation in ASW; a 5-HT group, injected with vehicle $10 \mathrm{~min}$ before a $2 \mathrm{~h}$ incubation in ASW containing 5-HT; and a $5-\mathrm{HT}+3 \mathrm{AB}$ group, which is the same as the 5-HT group with the injection containing $3 \mathrm{AB}$. Using differential display, we identified genes that are distinctly expressed in the groups immediately after the $2 \mathrm{~h}$ treatment, since ApC/EBP showed maximal upregulation at this time point. Among them we identified the $28 S$ rRNA (Fig. 5A, 275 bp band) and focused on the expression of rRNAs as genes activated by 5-HT and regulated by PARP activity. Total RNA from ganglia of each animal from the three groups was loaded, and rRNAs (18S and 28S) were quantified in RNA gels stained with ethidium bromide (Fig. 5B). The increases of rRNAs produced by 5-HT treatment (compare 5-HT group vs control group) were blocked by the injection of $3 \mathrm{AB}$ (compare 5-HT group vs 5-HT + 3AB) (Fig. 5C). PARP activity does not regulate the expression of all genes critical for LTF. The immediate early gene $A p C / E B P$ is upregulated by $5-\mathrm{HT}$, but inhibitors of PARP activity did not block the upregulation by 5 -HT (Fig. 5D). Thus, only a subset of genes induced by 5 -HT treatment is regulated by PARP activity.

Since PARP activity is required during and after 5-HT treatment for the expression of LTF at $24 \mathrm{~h}$ (Fig. 4), we examined the time course for the changes in rRNA expression after $2 \mathrm{~h}$ of 5-HT. 5 -HT produced an increase of rRNAs lasting for at least $20 \mathrm{~h}$ (Fig. $6 A, B)$.

In eukaryotes, the $18 \mathrm{~S}, 5.8 \mathrm{~S}$, and $28 \mathrm{~S}$ rRNAs are transcribed as a single RNA unit, which is edited during maturation (for review, see Fromont-Racine et al., 2003). The rate-limiting step of the editing is the trimming of a fraction of a noncoding sequence called internal transcribed spacer 2 (ITS2), which is up front of the $28 S$ rRNA (Perry, 1981). Since the pool of rRNAs in the cytosol is very abundant and can obscure ongoing transcriptional activity of the rDNA genes, we used the quantification of unedited $28 S$ ( $h t 28 S$ ) containing ITS2 as an indicator of newly synthesized rRNAs. ht $28 S$ is also upregulated in animals at $1,4,9$, and $20 \mathrm{~h}$ after the onset of 5-HT treatment (Fig. 6C). Interestingly at $2 \mathrm{~h}$, the $\mathrm{ht} 28 \mathrm{~S}$ seems to come down to control levels, although quantification of total rRNAs in the gels is higher (compare quantification at $2 \mathrm{~h}$ in Fig. $6 B, C)$. We also measured the mRNA levels of the immediate early gene $A p C / E B P$. As shown in Figure $6 D, A p C / E B P$ shows an early and transient upregulation, as reported previously (Alberini et al., 1994; Guan et al., 2002). Thus, our results indicate that treatment with 5-HT leads to dynamic and significant increases in rRNA expression.

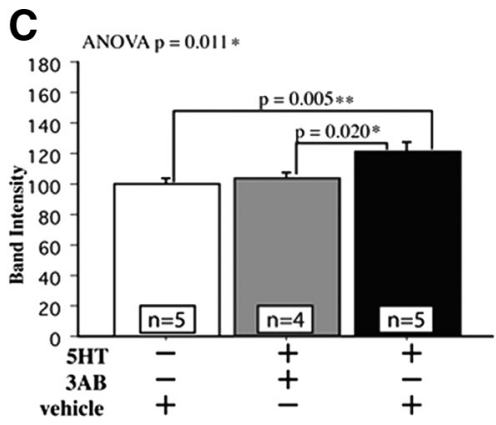

D KRUSKAL-WALLIS $p<0.001^{* * *}$

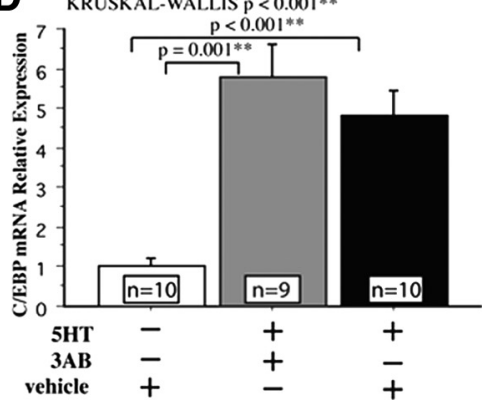

Figure 5. $3 A B$ blocks the upregulation of rRNA by $5-\mathrm{HT}$ but not the upregulation of the immediate early gene $A p C / E B P$. All nimals were injected $10 \mathrm{~min}$ before treatment with either vehicle (ASW) or $10 \mathrm{~mm} 3 \mathrm{AB}(1 \mathrm{ml} / 90 \mathrm{~g}$ of body mass) and were killed (that was upregulated when animals wels of $A p C / E B P$ when compared with animals injected with vehicle before 5-HT (black bar) (Mann-Whitney $U$ test, $p<$ 0.001 ) or animals injected with $3 \mathrm{AB}$ before $5-\mathrm{HT}$ (gray bar) (Mann-Whitney $U$ test, $p<0.001$ ). No significant difference was found between $5-\mathrm{HT}$ and $5-\mathrm{HT}+3 \mathrm{AB}$ groups.

In the quantification of the rRNAs in Figures 5 and 6 we standardized to the total RNA, but $70 \%$ of the total RNA is rRNA that is being regulated. It is therefore difficult to determine accurately the degree of changes in rRNA that is produced by $5-\mathrm{HT}$. To address this issue, we used pulse labeling of isolated pedalpleural ganglia to measure differences in rRNA synthesis as a second strategy to quantify the PARP-dependent increases $24 \mathrm{~h}$ after 5-HT treatment. In this method, we compared the pair of pedal-pleural ganglia from the same animals treated in two different conditions. We included the total mass of the ganglia for standardization, because it decreased the skewing effect of normalizing to total RNA, since total RNA is $<1 \%$ of the total mass. Pedal-pleural ganglia stimulated by five pulses of 5-HT compared with controls ( $n=11$ paired ganglia) showed a significant increase $(28.1 \% ; p<0.025)$ in the synthesis of new rRNAs $24 \mathrm{~h}$ later, whereas the synthesis of total RNA did not show significant differences ( $p>0.3$; data not shown). The increase in rRNA synthesis was PARP dependent, since the presence of $3 \mathrm{AB}(n=9$ paired ganglia) significantly reduced $(28.8 \%<5$-HT alone; $p<$ $0.05)$ rRNA synthesis at $24 \mathrm{~h}$ but did not reduce total RNA ( $p>$ $0.15)$. Since total RNA did not differ with treatments, by measuring the ratio of rRNA to total RNA we found that 5-HT produced a selective increase of rRNAs that was blocked by the PARP inhibitor ( $p<0.025$ and $<0.04$, respectively). Thus, PARP- 1 regulates the expression of transcripts required for the synthesis of new ribosomes. 


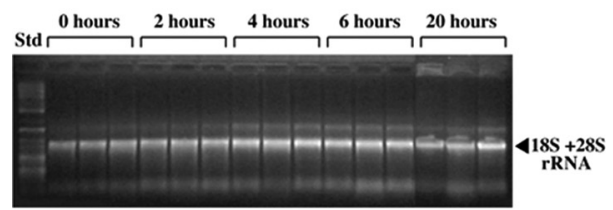

B
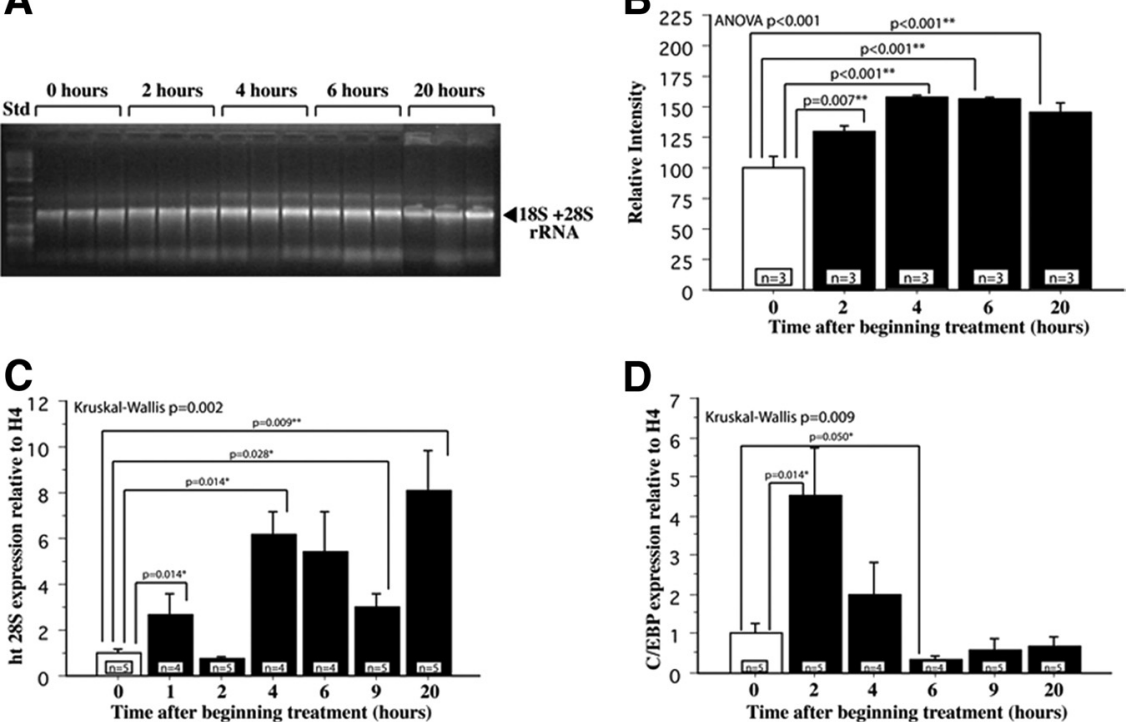

Figure 6. Dynamic regulation by $5-\mathrm{HT}$ of the expression of rRNAs (18S plus 28S) and its unedited precursor (ht 28S) up to $20 \mathrm{~h}$. $\boldsymbol{A}-\boldsymbol{C}, 5-\mathrm{HT}$ produced a long-lasting effect on rRNA expression, total rRNA $(\boldsymbol{A}, \boldsymbol{B})$, and its precursor ht $28 \mathrm{~S}(\boldsymbol{C})$. D, As a time course control, we used the relative levels of expression of the immediate early gene $A p C / E B P$. Animals treated with 5 -HT (black bars) were killed at different times after $2 \mathrm{~h}$ exposure to 5 -HT (except for the group treated for $1 \mathrm{~h}$ in $\mathrm{C}$ ). The control group was treated for $2 \mathrm{~h}$ in ASW (white bars). $A$, One milligram of total RNA from total ganglia from each animal was loaded in a $1 \%$ RNA gel. 5 -HT produced a persistent increase in the intensity of the 185 and 285 ribosomal RNA band (arrow). $\boldsymbol{B}$, Quantification of the RNA gel in $\boldsymbol{A}$ shows significant differences between untreated animals $(0 \mathrm{~h})$ and all treated groups ( $p$ values $=$ LSD). C , Quantification of ht $28 \mathrm{~S}$ by real-time PCR shows increases at $1,4,9$, and $20 \mathrm{~h}$ after the onset of 5 -HT compared with controls. $\boldsymbol{D}$, Increase in the expression of the immediate early gene $A P C / E B P$ quantified by real-time $P C R$ confirms early upregulation followed by a return to basal levels at later times.

\section{A}

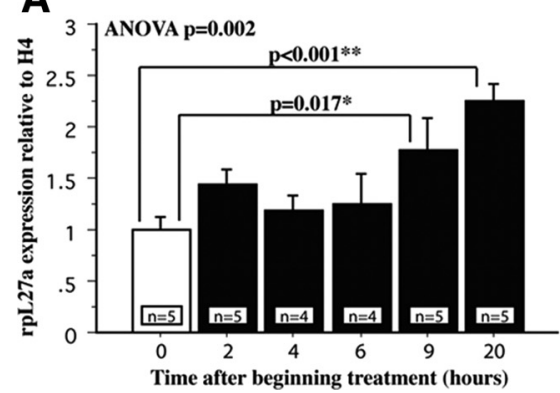

B

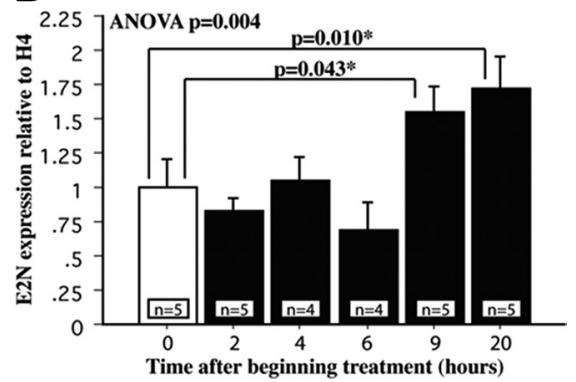

Figure 7. Expression of $r p L 27 a$ and ubiquitin-conjugating enzyme E2N mRNA expression is regulated after $5-H T$. A, Time course for changes in rpL27 expression is affected by 5 -HT (black). Expression of $r$ L27 $a$ increased significantly at later times ( 9 and $20 \mathrm{~h}$ ) relative to controls. $\boldsymbol{B}$, Time course for changes in E2N expression is affected by 5 -HT (black). Expression of E2N shows a pattern of upregulation after 5 - $\mathrm{HT}$ as that seen for $r$ L $27 \mathrm{a}$. There is a significant difference between control animals and 5 - $\mathrm{HT}$-treated animals at 9 and $20 \mathrm{~h}$.

\section{5-HT produces changes in expression of both AprpL27a and ApE2N mRNAs}

Since PARP activity and new protein synthesis are required for LTF, and PARP activity is necessary for the regulation of rRNA expression after 5-HT, we tested whether expression of other parts of the translational machinery may be regulated by $5-\mathrm{HT}$. We measured the levels of expression of two uncharacterized Aplysia mRNAs: the Aplysia ribosomal protein ApL27a and its regulator $A p \mathrm{E} 2 \mathrm{~N}$. In eukaryotes, rpL27a is important for translocation during protein synthesis and $\mathrm{E} 2 \mathrm{~N}$ is important for lysine 63 (K63) polyubiquitination of rpL27a (Spence et al., 2000). Both mRNAs were upregulated at 9 and $20 \mathrm{~h}$ after the onset of 5-HT treatment (Fig. 7). Thus, several components of ribosomes and the translation machinery are regulated by 5-HT.

\section{Discussion}

Our results indicate that PARP-1 is necessary for LTF of sensorimotor neuron synapses, one cellular analog of LTM for sensitization in Aplysia. In contrast, PARP-1 is not essential for short-term facilitation, a cellular analog of short-term memory that requires only posttranslational modification of pre-existing molecules (Kandel and Schwartz, 1982). These results extend a previous report that showed PARP activity was necessary for LTM in Aplysia and that PARP-1 was activated after 5-HT treatment of intact ganglia (Cohen-Armon et al., 2004).

In an operant conditioning task that affects feeding, PARP inhibition blocked long-term memory but not short-term memory. PARP-1 becomes active in the buccal-cerebral ganglia, the main ganglia regulating feeding responses. PARP-1 becomes activated in pleural-pedal ganglia after sensitization of the siphon-tail withdrawal reflex or treatment of those ganglia with five pulses of 5-HT. In addition, polyADP-ribosylation of histone $\mathrm{H} 1$ was observed in ganglia after 5-HT, and this suggested that PARP-1 activity is necessary for chromatin decondensation (CohenArmon et al., 2004). PARP is a family of enzymes, and currently there is no specific inhibitor for PARP-1. The only way to demonstrate that this enzyme is necessary for long-term synaptic plasticity is by disrupting its expression. The cloning of ApPARP-1 and the blocking of LTF by injection of antisense oligonucleotides into the presynaptic sensory neurons indicated that PARP-1 expression in the sensory neuron is necessary for LTF of sensorimotor neuron synapses, a cellular analog of LTM for sensitization in Aplysia that requires protein synthesis and gene expression (Kandel, 2001).

PARP activity contributes to alterations in chromatin structure and gene expression in a variety of cells, including neurons (Jones et al., 2001; Tulin et al., 2002; Tulin and Spradling, 2003; Cohen-Armon et al., 2004; for review, see Cohen-Armon, 2007; Kauppinen and Swanson, 2007). Because most forms of long-term synaptic plasticity require both new gene expression and new protein synthesis (Davis and Squire, 1984; Kandel, 2001), our results indicate that PARP-1 activity plays a critical role in regulating stimulus-induced changes in macromolecular synthesis required for LTF. We observed that 5-HT treatments that evoke LTF produced a PARP-dependent increase of rRNAs and increases in other components associated with translation. Thus, PARP-1 expression and activity contribute to the increase in essential components of the translational machinery that may be critical for synthesizing the new proteins required for LTF. 


\section{PARP expression and activity are required for LTF and regulation of specific genes}

The sequence of Aplysia PARP-1 (ApPARP-1) is homologous to that of PARP-1 identified in other species, including vertebrates, and therefore is likely to have conserved functions. In pathophysiological conditions, PARP activity allows decondensation of chromatin critical for DNA repair. This relaxation of DNA structure provides access of bulky DNA repair enzymes to the damaged site (for review, see D'Amours et al., 1999). PARP activity also functions in regulating gene expression in both neural and non-neural cells (Jones et al., 2001; Ha et al., 2002; Ju et al., 2004, 2006; Pavri et al., 2005; Kauppinen and Swanson, 2007; Ogino et al., 2007) and may do so through chromatin remodeling (Tulin et al., 2002; Tulin and Spradling, 2003; Schreiber et al., 2006; Cohen-Armon et al., 2007; Krishnakumar et al., 2008). Chromatin remodeling is an essential step in the regulation of gene expression in both non-neuronal and neuronal cell types (for review, see Narlikar et al., 2002; Levenson and Sweatt, 2006). In the nervous system, alteration in chromatin structure is important for regulating the expression of genes required for long-term synaptic plasticity and learning and memory (Levenson and Sweatt, 2006). In Aplysia, CREB phosphorylation by PKA and other kinases activated by stimulation is necessary for the expression of the immediate early gene $C / E B P$, a transcription factor required for the expression of late genes that contribute to synaptic plasticity. This activation requires chromatin remodeling through histone acetylation at the promoter region of $C / E B P$ (Guan et al., 2002).

In this report, we showed that the expression and activity of the enzyme PARP-1 is also necessary for LTF in Aplysia. PARP activity regulates the expression of a subset of genes independently of histone acetylation/deacetylation, since the 5-HT regulation of $A p C / E B P$ was not affected by blocking PARP activity (Figs. 5, 6). In contrast, PARP activity was required for the 5-HTdependent increase of rRNAs. This regulation may be mediated by chromatin remodeling at the promoter region of rRNA genes, since Aplysia histone $\mathrm{H} 1$ is polyADP ribosylated by $5-\mathrm{HT}$ (Cohen-Armon et al., 2004). An increase of rRNA synthesis in chick cochlear neurons was also found to be activity dependent (Hyson and Rubel, 1995). Thus, PARP activation may be permissive in regulating genes involved with the new translation required for various forms of long-term synaptic plasticity or LTM.

\section{Persistent PARP activity produces LTF and persistent changes in gene expression}

The requirement of ongoing PARP activity after 5-HT treatment (Fig. 4) was unexpected, since PARP inhibitors blocked $24 \mathrm{~h} \mathrm{LTM}$ when injected into intact animals before, but not after, short operant conditioning training of feeding behavior (CohenArmon et al., 2004). Perhaps different forms of long-term synaptic plasticity have different critical time windows for the enzyme to act. This ongoing enzyme activity by PARP may account for the persistent and dynamic increase in rRNA synthesis for $>20 \mathrm{~h}$ (Fig. 6). Treatment with 5-HT is known to activate several waves of protein synthesis that are required for forms of LTF that last 3-7 d after stimulation (Barzilai et al., 1989; Giustetto et al., 2003; Miniaci et al., 2008). These waves of protein expression may be regulated by stimulus-dependent recruitment of additional factors required for LTF, such as the 5-HT-induced secretion of the neuropeptide sensorin, which activates and translocates ERK1/2 into sensory neuron nuclei (Hu et al., 2004, 2007). Activity of PARP-1 in neurons is regulated directly by ERK1/2 phosphorylation (Kauppinen et al., 2006) or by protein-protein interaction with activated ERK1/2 (Cohen-Armon et al., 2007). The activity of $A p$ PARP- 1 may be regulated by phosphorylation by ERK $1 / 2$ or the other kinases that are persistently activated by 5 -HT, such PKA and PKC (Bergold et al., 1992; Sossin et al., 1994; Chain et al., 1995, 1999). ApPARP-1 contains multiple putative phosphorylation sites for these kinases (supplemental Table 2, available at www.jneurosci.org as supplemental material). Thus, dynamic and long-lasting regulation by PARP of rRNA synthesis may accommodate the multiple waves of protein synthesis required for long-lasting forms of LTF.

\section{PARP control of ribosomal machinery and synaptic plasticity} New protein synthesis, both in the cell body and at distal synaptic sites, is critical for long-term synaptic plasticity. The regulation of this translation is typically under the tight control of cis elements at the $5^{\prime}$ or $3^{\prime}$ untranslated regions, as seen for the translation of those mRNAs controlled by the target of rapamycin (mTOR) pathway (for review, see Klann and Sweatt, 2008). Interestingly, the mTOR pathway has been shown to control rRNA transcription during the cell cycle (Grummt, 2003; Russell and Zomerdijk, 2005). The current view of activity-dependent long-term synaptic plasticity is that the population of ribosomes in the cytosol is stable. However, nucleoli, the site of rRNA synthesis, can be modulated by a number of factors. Spatial learning induced an increase in the argyrophilic nucleolar organizer regions (AgNORs) of dorsolateral telencephalic neurons in goldfish (Vargas et al., 2000). The AgNOR is a region within the nucleolus responsible for rRNA synthesis. After prolonged neural activity, a cleaved form of the protein AIDA-1d, a component of the PSD (postsynaptic density) in neurons, travels to the nucleus to produce an increase in nucleolar number, suggesting a regulation of the protein biosynthetic capacity of neurons in response to activity (Jordan et al., 2007). Knockdowns of PARP-1, an enzyme enriched in nucleoli (Meder et al., 2005), are embryonic lethal and result in the disappearance of nucleoli (Tulin et al., 2002). We demonstrate here that 5-HT stimulated a highly dynamic and longlasting increase in the expression of rRNAs that depends on PARP activity (Fig. 6). Because RNA polymerase I, a major constituent of nucleoli, is the major enzyme for rRNA synthesis (Russell and Zomerdijk, 2005), our results suggest that PARP-1 is an important regulator of RNA polymerase I transcription during longterm synaptic plasticity.

The expression of mRNA encoding Aplysia ribosomal protein L27a is upregulated by 5-HT (Fig. 7), suggesting that the overall expression of the ribosomal machinery is affected during LTF. In addition, the expression of mRNA encoding the Aplysia enzyme $\mathrm{E} 2 \mathrm{~N}$, an enzyme that by polyubiquinating rpL27a increases the efficiency of translation (Spence et al., 2000), is upregulated (Fig. 7). ApE2N and AprpL27a may also be necessary for long-term synaptic plasticity as other regulators of translation, such as ApEF1A (Giustetto et al., 2003). Further studies are necessary to reveal whether the newly synthesized ribosomes induced by $5-\mathrm{HT}$ are a critical component of RNA granules containing specific newly synthesized mRNAs whose translation is important for long-lasting forms of synaptic plasticity.

\section{References}

Aalfs JD, Kingston RE (2000) What does 'chromatin remodeling' mean? Trends Biochem Sci 25:548-555.

Alberini CM, Ghirardi M, Metz R, Kandel ER (1994) C/EBP is an immediate-early gene required for the consolidation of long-term facilitation in Aplysia. Cell 76:1099-1114.

Bartsch D, Ghirardi M, Casadio A, Giustetto M, Karl KA, Zhu H, Kandel ER (2000) Enhancement of memory-related long-term facilitation by ApAF, 
a novel transcription factor that acts downstream from both CREB1 and CREB2. Cell 103:595-608.

Barzilai A, Kennedy TE, Sweatt JD, Kandel ER (1989) 5-HT modulates protein synthesis and the expression of specific proteins during long-term facilitation in Aplysia sensory neurons. Neuron 2:1577-1586.

Bergold PJ, Beushausen SA, Sacktor TC, Cheley S, Bayley H, Schwartz JH (1992) A regulatory subunit of the cAMP-dependent protein kinase down-regulated in Aplysia sensory neurons during long-term sensitization. Neuron 8:387-397.

Buonomano DV, Byrne JH (1990) Long-term synaptic changes produced by a cellular analog of classical conditioning in Aplysia. Science 249:420-423.

Chain DG, Hegde AN, Yamamoto N, Liu-Marsh B, Schwartz JH (1995) Persistent activation of cAMP-dependent protein kinase by regulated proteolysis suggests a neuron-specific function of the ubiquitin system in Aplysia. J Neurosci 15:7592-7603.

Chain DG, Casadio A, Schacher S, Hegde AN, Valbrun M, Yamamoto N, Goldberg AL, Bartsch D, Kandel ER, Schwartz JH (1999) Mechanisms for generating the autonomous cAMP-dependent protein kinase required for long-term facilitation in Aplysia. Neuron 22:147-156.

Cohen-Armon M (2007) PARP-1 activation in the ERK signaling pathway. Trends Pharmacol Sci 28:556-560.

Cohen-Armon M, Visochek L, Katzoff A, Levitan D, Susswein AJ, Klein R, Valbrun M, Schwartz JH (2004) Long-term memory requires polyADPribosylation. Science 304:1820-1822.

Cohen-Armon M, Visochek L, Rozensal D, Kalal A, Geistrikh I, Klein R, Bendetz-Nezer S, Yao Z, Seger R (2007) DNA-independent PARP-1 activation by phosphorylated ERK2 increases Elk1 activity: a link to histone acetylation. Mol Cell 25:297-308.

Dale N, Kandel ER, Schacher S (1987) Serotonin produces long-term changes in the excitability of Aplysia sensory neurons in culture that depend on new protein synthesis. J Neurosci 7:2232-2238.

D’Amours D, Desnoyers S, D’Silva I, Poirier GG (1999) Poly(ADPribosyl)ation reactions in the regulation of nuclear functions. Biochem J 342:249-268.

Davis HP, Squire LR (1984) Protein synthesis and memory: a review. Psychol Bull 96:518-559.

de Murcia G, Ménissier de Murcia J (1994) Poly(ADP-ribose) polymerase: a molecular nick-sensor. Trends Biochem Sci 19:172-176.

Fioravante D, Liu RY, Byrne JH (2008) The ubiquitin-proteasome system is necessary for long-term synaptic depression in Aplysia. J Neurosci 28:10245-10256.

Fromont-Racine M, Senger B, Saveanu C, Fasiolo F (2003) Ribosome assembly in eukaryotes. Gene 313:17-42.

Fulton D, Kemenes I, Andrew RJ, Benjamin PR (2005) A single timewindow for protein synthesis-dependent long-term memory formation after one-trial appetitive conditioning. Eur J Neurosci 21:1347-1358.

Giustetto M, Hegde AN, Si K, Casadio A, Inokuchi K, Pei W, Kandel ER, Schwartz JH (2003) Axonal transport of eukaryotic translation elongation factor 1alpha mRNA couples transcription in the nucleus to long-term facilitation at the synapse. Proc Natl Acad Sci U S A 100: $13680-13685$.

Grummt I (2003) Life on a planet of its own: regulation of RNA polymerase I transcription in the nucleolus. Genes Dev 17:1691-1702.

Guan Z, Giustetto M, Lomvardas S, Kim JH, Miniaci MC, Schwartz JH, Thanos D, Kandel ER (2002) Integration of long-term-memory-related synaptic plasticity involves bidirectional regulation of gene expression and chromatin structure. Cell 111:483-493.

Guan Z, Kim JH, Lomvardas S, Holick K, Xu S, Kandel ER, Schwartz JH (2003) p38 MAP kinase mediates both short-term and long-term synaptic depression in Aplysia. J Neurosci 23:7317-7325.

Ha HC, Hester LD, Snyder SH (2002) Poly(ADP-ribose) polymerase-1 dependence of stress-induced transcription factors and associated gene expression in glia. Proc Natl Acad Sci U S A 99:3270-3275.

Hattar S, Lyons LC, Eskin A (2002) Circadian regulation of a transcription factor, ApC/EBP, in the eye of Aplysia californica. J Neurochem 83:1401-1411.

Hegde AN, Inokuchi K, Pei W, Casadio A, Ghirardi M, Chain DG, Martin KC, Kandel ER, Schwartz JH (1997) Ubiquitin C-terminal hydrolase is an immediate-early gene essential for long-term facilitation in Aplysia. Cell $89: 115-126$.

Homburg S, Visochek L, Moran N, Dantzer F, Priel E, Asculai E, Schwartz D,
Rotter V, Dekel N, Cohen-Armon M (2000) A fast signal-induced activation of Poly(ADP-ribose) polymerase: a novel downstream target of phospholipase c. J Cell Biol 150:293-307.

Hu JY, Glickman L, Wu F, Schacher S (2004) Serotonin regulates the secretion and autocrine action of a neuropeptide to activate MAPK required for long-term facilitation in Aplysia. Neuron 43:373-385.

Hu JY, Chen Y, Schacher S (2007) Protein kinase C regulates local synthesis and secretion of a neuropeptide required for activity-dependent longterm synaptic plasticity. J Neurosci 27:8927-8939.

Hyson RL, Rubel EW (1995) Activity-dependent regulation of a ribosomal RNA epitope in the chick cochlear nucleus. Brain Res 672:196-204.

Jones CB, McIntosh J, Huang H, Graytock A, Hoyt DG (2001) Regulation of bleomycin-induced DNA breakage and chromatin structure in lung endothelial cells by integrins and poly(ADP-ribose) polymerase. Mol Pharmacol 59:69-75.

Jordan BA, Fernholz BD, Khatri L, Ziff EB (2007) Activity-dependent AIDA-1 nuclear signaling regulates nucleolar numbers and protein synthesis in neurons. Nat Neurosci 10:427-435.

Ju BG, Solum D, Song EJ, Lee KJ, Rose DW, Glass CK, Rosenfeld MG (2004) Activating the PARP-1 sensor component of the groucho/ TLE1 corepressor complex mediates a CaMKinase IIdelta-dependent neurogenic gene activation pathway. Cell 119:815-829.

Ju BG, Lunyak VV, Perissi V, Garcia-Bassets I, Rose DW, Glass CK, Rosenfeld MG (2006) A topoisomerase IIbeta-mediated dsDNA break required for regulated transcription. Science 312:1798-1802.

Kameshita I, Matsuda Z, Taniguchi T, Shizuta Y (1984) Poly (ADP-ribose) synthetase. Separation and identification of three proteolytic fragments as the substrate-binding domain, the DNA-binding domain, and the automodification domain. J Biol Chem 259:4770-4776.

Kandel ER (2001) The molecular biology of memory storage: a dialogue between genes and synapses. Science 294:1030-1038.

Kandel ER, Schwartz JH (1982) Molecular biology of learning: modulation of transmitter release. Science 218:433-443.

Kauppinen TM, Swanson RA (2007) The role of poly(ADP-ribose) polymerase-1 in CNS disease. Neuroscience 145:1267-1272.

Kauppinen TM, Chan WY, Suh SW, Wiggins AK, Huang EJ, Swanson RA (2006) Direct phosphorylation and regulation of poly(ADP-ribose) polymerase-1 by extracellular signal-regulated kinases $1 / 2$. Proc Natl Acad Sci U S A 103:7136-7141.

Kim MY, Zhang T, Kraus WL (2005) Poly(ADP-ribosyl)ation by PARP-1: 'PAR-laying' NAD + into a nuclear signal. Genes Dev 19:1951-1967.

Klann E, Sweatt JD (2008) Altered protein synthesis is a trigger for longterm memory formation. Neurobiol Learn Mem 89:247-259.

Krishnakumar R, Gamble MJ, Frizzell KM, Berrocal JG, Kininis M, Kraus WL (2008) Reciprocal binding of PARP-1 and histone $\mathrm{H} 1$ at promoters specifies transcriptional outcomes. Science 319:819-821.

Levenson JM, Sweatt JD (2006) Epigenetic mechanisms: a common theme in vertebrate and invertebrate memory formation. Cell Mol Life Sci 63:1009-1016.

Lyons LC, Collado MS, Khabour O, Green CL, Eskin A (2006) The circadian clock modulates core steps in long-term memory formation in Aplysia. J Neurosci 26:8662-8671.

Mauelshagen J, Parker GR, Carew TJ (1996) Dynamics of induction and expression of long-term synaptic facilitation in Aplysia. J Neurosci 16:7099-7108.

Meder VS, Boeglin M, de Murcia G, Schrieber V (2005) PARP-1 and PARP-2 interact with nucleophosmin/B23 and accumulate in transcriptionally active nucleoli. J Cell Sci 118:211-222.

Miniaci MC, Kim JH, Puthanveettil SV, Si K, Zhu H, Kandel ER, Bailey CH (2008) Sustained CPEB-dependent local protein synthesis is required to stabilize synaptic growth for persistence of long-term facilitation in Aplysia. Neuron 59:1024-1036.

Montarolo PG, Goelet P, Castellucci VF, Morgan J, Kandel ER, Schacher S (1986) A critical period for macromolecular synthesis in long-term heterosynaptic facilitation in Aplysia. Science 234:1249-1254.

Montarolo PG, Kandel ER, Schacher S (1988) Long-term heterosynaptic inhibition in Aplysia. Nature 333:171-174.

Moroz LL, Edwards JR, Puthanveettil SV, Kohn AB, Ha T, Heyland A, Knudsen B, Sahni A, Yu F, Liu L, Jezzini S, Lovell P, Iannucculli W, Chen M, Nguyen T, Sheng H, Shaw R, Kalachikov S, Panchin YV, Farmerie W, Russo JJ, Ju J, Kandel ER (2006) Neuronal transcriptome of Aplysia: neuronal compartments and circuitry. Cell 127:1453-1467. 
Narlikar GJ, Fan HY, Kingston RE (2002) Cooperation between complexes that regulate chromatin structure and transcription. Cell 108:475-487.

Noel F, Nuñez-Regueiro M, Cook R, Byrne JH, Eskin A (1993) Long-term changes in synthesis of intermediate filament protein, actin and other proteins in pleural sensory neurons of Aplysia produced by an in vitro analogue of sensitization training. Brain Res Mol Brain Res 19:203-210.

Noel F, Koumenis C, Nunez-Regueiro M, Raju U, Byrne JH, Eskin A (1994) Effects on protein synthesis produced by pairing depolarization with serotonin, an analogue of associative learning in Aplysia. Proc Natl Acad Sci U S A 91:4150-4154.

Ogino H, Nozaki T, Gunji A, Maeda M, Suzuki H, Ohta T, Murakami Y, Nakagama H, Sugimura T, Masutani M (2007) Loss of Parp-1 affects gene expression profile in a genome-wide manner in ES cells and liver cells. BMC Genomics 8:41.

Pavri R, Lewis B, Kim TK, Dilworth FJ, Erdjument-Bromage H, Tempst P, de Murcia G, Evans R, Chambon P, Reinberg D (2005) PARP-1 determines specificity in a retinoid signaling pathway via direct modulation of mediator. Mol Cell 18:83-96.

Perry RP (1981) RNA processing comes of age. J Cell Biol 91:28s-38s.

Polesskaya OO, Haroutunian V, Davis KL, Hernandez I, Sokolov BP (2003) Novel putative nonprotein-coding RNA gene from 11q14 displays decreased expression in brains of patients with schizophrenia. J Neurosci Res 74:111-122.

Russell J, Zomerdijk JC (2005) RNA-polymerase-I-directed rDNA transcription, life and works. Trends Biochem Sci 30:87-96.

Schreiber V, Dantzer F, Ame JC, de Murcia G (2006) Poly(ADP-ribose): novel functions for an old molecule. Nat Rev Mol Cell Biol 7:517-528.

Sharma SK, Carew TJ (2004) The roles of MAPK cascades in synaptic plasticity and memory in Aplysia: facilitatory effects and inhibitory constraints. Learn Mem 11:373-378

Sokolov BP, Prockop DJ (1994) A rapid and simple PCR-based method for isolation of cDNAs from differentially expressed genes. Nucleic Acids Res 22:4009-4015.

Sossin WS, Sacktor TC, Schwartz JH (1994) Persistent activation of protein kinase C during the development of long-term facilitation in Aplysia. Learn Mem 1:189-202.

Spence J, Gali RR, Dittmar G, Sherman F, Karin M, Finley D (2000) Cell cycle-regulated modification of the ribosome by a variant multiubiquitin chain. Cell 102:67-76.

Sutton MA, Carew TJ (2000) Parallel molecular pathways mediate expression of distinct forms of intermediate-term facilitation at tail sensorymotor synapses in Aplysia. Neuron 26:219-231.

Sutton MA, Bagnall MW, Sharma SK, Shobe J, Carew TJ (2004) Intermediateterm memory for site-specific sensitization in Aplysia is maintained by persistent activation of protein kinase C. J Neurosci 24:3600-3609.

Tulin A, Spradling A (2003) Chromatin loosening by poly(ADP)-ribose polymerase (PARP) at Drosophila puff loci. Science 299:560-562.

Tulin A, Stewart D, Spradling AC (2002) The Drosophila heterochromatic gene encoding poly(ADP-ribose) polymerase (PARP) is required to modulate chromatin structure during development. Genes Dev 16:2108-2119.

Vargas JP, Rodríguez F, López JC, Arias JL, Salas C (2000) Spatial learninginduced increase in the argyrophilic nucleolar organizer region of dorsolateral telencephalic neurons in goldfish. Brain Res 865:77-84.

Virág L, Szabó C (2002) The therapeutic potential of poly(ADP-ribose) polymerase inhibitors. Pharmacol Rev 54:375-429.

Visochek L, Steingart RA, Vulih-Shultzman I, Klein R, Priel E, Gozes I, Cohen-Armon M (2005) PolyADP-ribosylation is involved in neurotrophic activity. J Neurosci 25:7420-7428.

Zwartjes RE, West H, Hattar S, Ren X, Noel F, Nuñez-Regueiro M, MacPhee K, Homayouni R, Crow MT, Byrne JH, Eskin A (1998) Identification of specific mRNAs affected by treatments producing long-term facilitation in Aplysia. Learn Mem 4:478-495. 